\title{
Quantificação de taninos presentes na casca da Mimosa caealpiniifolia Benth. e sua utilização no tratamento de efluentes ${ }^{1}$
}

\author{
Diná Garcia de SOUZA²*, Débora Baiocchi Princivalli CAMPOS², João Gilberto Mesa UCELLA FILHO², \\ João Paulo Silva GOMES², Tatiane Kelly Barbosa de AZEVEDO²
}

\author{
${ }^{1}$ Trabalho selecionado no VI Congresso Nordestino de Engenharia Florestal, Mossoró, RN, Brasil. \\ ${ }^{2}$ Universidade Federal do Rio Grande do Norte, Macaíba, Rio Grande do Norte, Brasil. \\ ${ }^{3}$ Universidade Federal de Lavras, Minas Gerais, Brasil. \\ *E-mail: garcia7dina@gmail.com
}

Recebido em maio/2019; Aceito em junho/2019.

\begin{abstract}
RESUMO: Este estudo teve por objetivo analisar as concentrações de taninos existentes na casca das árvores da Mimosa caealpiniifolia Benth., e seu potencial para tratamentos de efluentes. As cascas foram retiradas de cinco árvores de uma área experimental localizada na Universidade Federal do Rio Grande do Norte, Campus Macaíba. Estas foram secas e moídas para redução de sua granulometria. Em seguida foram realizados a extração dos taninos e determinação do teor de sólidos totais (TST), teor de taninos condensados (TTC) e índice de Stiasny (I). Para caracterização do efluente foi analisado o índice de turbidez/NTU, pH inicial e cor aparente. O valor médio encontrado para TST, I e TTC foram, respectivamente, $11,30,71,43$ e $6,56 \%$. O índice de turbidez/NTU e $\mathrm{pH}$, encontrados foram 1,77 e 5 , respectivamente. Os taninos sem modificações químicas têm pouca eficiência na remoção de turbidez, no entanto, foi comprovado que o tanino possui aptidão a coagular.
\end{abstract}

Palavras-chave: coagulante; floculação; substâncias tânicas; Caatinga.

\section{Quantification of tannins present in the bark of Mimosa caealpiniifolia Benth. and its use in effluent treatment}

\begin{abstract}
This study aimed to analyze the concentrations of tannins in the bark of Mimosa caealpiniifolia Benth. trees, and their potential for effluent treatment. The bark was removed from five trees in an experimental area located at the Federal University of Rio Grande do Norte, Campus Macaíba. They were dried and ground to reduce their granulometry. Next, tannin extraction and determination of total solids content (TST), condensed tannin content (TTC) and Stiasny index (I) were performed. To characterize the effluent, the turbidity index/NTU, initial $\mathrm{pH}$ and apparent color were analyzed. The mean value found for TST, I and TTC were, respectively, 11.30, 71.43 and $6.56 \%$. The turbidity/NTU and $\mathrm{pH}$ index found were 1.77 and 5, respectively. The tannin without chemical modifications has little efficiency in removing turbidity, however, it has been proven that the tannin has ability to coagulate.
\end{abstract}

Keywords: coagulant; flocculation; tannic substances; Caatinga.

\section{INTRODUÇÃO}

A extensão territorial da Região Semiárida Brasileira apresenta uma área de aproximadamente $844.453 \mathrm{Km}^{2}$, o equivalente a $11 \%$ do território nacional, e apesar da grande abrangência, proporcionalmente, é o menos estudado e protegido das composições florísticas brasileiras, sendo que sua biodiversidade ampara diversas atividades econômicas voltadas para fins agrossilvipastoris e industriais, especialmente nos ramos farmacêutico, de cosméticos, químico e de alimentos (MMA, 2016).

A Caatinga tem papel relevante como fornecedora de produtos madeireiros (lenha, estacas e material para construções diversas), e não madeireiros, a exemplo dos taninos vegetais, que podem ser encontrados em várias partes do vegetal, como madeira, casca, frutos e sementes. Espécies da região se destacam por apresentar elevado percentual de teor de taninos condensados, a exemplo da Jurema-vermelha (18,11\%), Jurema-preta (17,74\%), Angico vermelho (11,89\%) e o Cajueiro (19,83\%) (PAES et al., 2006a; GONÇALVES; LELIS, 2001).
Os taninos são constituídos por polifenóis e classificados em taninos hidrolisáveis e taninos condensados. Os hidrolisáveis são poliésteres da glicose e são classificados, dependendo do ácido formado de sua hidrólise, em galo ou elágico taninos (PIZZI, 1993). Os taninos condensados são constituídos por monômeros do tipo catequina e são conhecidos por flavonóides (HASLAM, 1966; WENZL, 1970; PIZZI, 1993), estando presentes, basicamente, na casca das árvores, e podem representar de 2 a $40 \%$ da massa seca da casca de várias espécies florestais (PAES et al., 2006a).

No mercado mundial de taninos vegetais as espécies que mais se destacam são o quebracho e a tara. Enquanto no Brasil a espécie maior produtora de taninos é a Acacia mearnsii Willd., com uma produção em 2016 de 195.913 t de casca (IBGE, 2017). Além da importância no curtimento de couros e peles, os taninos condensados vêm sendo estudados e caracterizados visando a sua aplicação como inibidores de corrosão (D'ALESSANDRO et al., 2018), sendo, também, empregados na fabricação de tintas e adesivos especiais para 
colagem de madeira e derivados (AZEVÊDO et al., 2015; SANTIAGO et al., 2018).

No Brasil, o adesivo de taninos de acácia-negra (Acacia mearnsii) é produzido em escala comercial para colagem de compensados e aglomerados (KEINERT JUNIOR; WOLF, 1984; PIZZI, 1993). Em função disto, várias pesquisas vêm sendo desenvolvidas visando a utilização de taninos para adesivos (CARNEIRO et al., 2012). Além disso, em virtude de suas propriedades, vêm sendo pesquisadas suas atividades antimicrobiana e antiaderente em bactérias dentárias (MENEZES et al., 2014;) e para fabricação de floculantes e/ou coagulantes e auxiliares de floculação para reuso e tratamento de águas e efluentes industriais (BELTRÁN-HEREDIA et al., 2010; FERNANDES et al., 2015; HAMEED et al., 2018; LOPES et al., 2019).

$\mathrm{O}$ desenvolvimento de tecnologias alternativas para tratar os efluentes tem contribuído para a gerência da qualidade ambiental. Uma das alternativas de tratamento hoje estuda a utilização de coagulantes naturais derivados de fontes renováveis, como aqueles retirados de plantas, o qual representa um grande desenvolvimento nas questões sustentáveis e tecnológicas ambientais (MARTINS et al., 2014).

Diante da importância socioeconômica da vegetação da Região Semiárida brasileira, e em busca de alternativas quanto as partes da planta fornecedora de taninos, e sua utilização, este estudo teve como objetivo analisar as concentrações de taninos existentes na casca das árvores da Mimosa caealpiniifolia Benth. e seu potencial no tratamento de efluentes.

\section{MATERIAL E MÉTODOS}

Para este estudo foram utilizadas cinco plantas de sabiá (Mimosa caesalpiniifolia), escolhidas em plantio, com 6 (seis) anos de idade, que vegetam no Campus de Macaíba, na Escola Agrícola de Jundiaí - EAJ/ Universidade Federal do Rio Grande do Norte - UFRN. As árvores estudadas foram selecionadas em função do vigor, sendo escolhidas aquelas com ausência de ataque de pragas e doenças.

Foram coletados dois quilos de cascas distribuídas aleatoriamente no tronco de cada árvore, com o auxílio de facões. As cascas foram postas para secar em estufa solar $\left(45 \pm 5^{\circ} \mathrm{C}\right)$ para a determinação do Teor de Umidade (TU) de cada indivíduo. Após isto, foram moídas em moinho do tipo Willey, para obter um material de menor granulometria. Os materiais foram classificados e foi utilizada a porção que passou pela peneira de 16 "mesh" $(1,00 \mathrm{~mm})$, e ficou retida na de 60 "mesh" (0,25 mm).

A serragem obtida foi homogeneizada e o teor de umidade (base seca) determinado, para permitir os cálculos, em base seca, do teor de taninos presentes em cada amostra. As substâncias tânicas contidas nos materiais foram extraídas em água destilada. Para as extrações foram tomadas, de cada material, três amostras de $25 \mathrm{~g}$ de material seco. As amostras foram transferidas para balões de fundo chato com capacidade de $500 \mathrm{~mL}$, aos quais foram adicionados $250 \mathrm{~mL}$ de água destilada (relação 1:10 p/v) e submetidas à fervura, sob refluxo, por duas horas.

Cada amostra foi submetida a duas sequências de extrações, a fim de se retirar à máxima quantidade de extrativos presentes. Após cada extração, o material foi passado em uma peneira de 150 "mesh" $(0,105 \mathrm{~mm})$ e em um tecido de flanela, para a retenção de partículas de serragem. $\mathrm{O}$ extrato obtido foi homogeneizado e filtrado em funil de vidro sintetizado de porosidade 2 .

Em seguida, foi concentrado para $250 \mathrm{~mL}$ pela evaporação da água ao empregar um aparelho tipo Soxhlet. Após a concentração três alíquotas de $50 \mathrm{~mL}$ foram retiradas de cada extrato. Duas alíquotas foram utilizadas para a determinação do teor de taninos condensados (TTC) e a outra foi evaporada em estufa a $103 \pm 2{ }^{\circ} \mathrm{C}$ por 48 horas, para a determinação da porcentagem de teor de sólidos totais (TST) (Equação 1).

$$
\mathrm{TST}=(\mathrm{Mi}-\mathrm{Mf}) * 100
$$

em que: TST $=$ Teor de sólidos totais; $\mathrm{Mi}=$ Massa seca da amostra em gramas; $\mathrm{Mf}=$ Massa do extrato, após a secagem, em gramas.

Para a determinação do teor de taninos condensados (TTC), presente em cada amostra foi empregado o método de Stiasny, descrito por Guangcheng et al. (1991). Para tanto, aos $50 \mathrm{~mL}$ do extrato bruto serão adicionados $4 \mathrm{~mL}$ de formaldeído $(37 \% \mathrm{~m} / \mathrm{m})$ e $1 \mathrm{~mL}$ de ácido clorídrico concentrado. Cada mistura foi submetida à fervura sob refluxo por 30 minutos. Nestas condições, os taninos formam complexos insolúveis que podem ser separados por filtração simples. Para este caso, foi empregado filtro de papel posto em funil de Büchner de 10 $\mathrm{cm}$ de diâmetro e $4 \mathrm{~cm}$ de profundidade. $\mathrm{O}$ material retido no filtro foi seco em estufa a $103 \pm 2{ }^{\circ} \mathrm{C}$ por 24 horas, em seguida foi calculado o índice de Stiasny (Equação 2).

$$
\mathrm{I}=\frac{\mathrm{M} 2}{\mathrm{M} 1} * 100
$$

em que: I = Índice de Stiasny em porcentagem; M1 = Massa de sólidos em $50 \mathrm{~mL}$ de extrato; M2 = Massa do precipitado taninos formaldeído.

A quantidade de taninos presente em cada amostra foi obtida ao multiplicar o índice de Stiasny pelo teor de sólidos totais (Equação 3).

$$
\operatorname{TST}(\%)=\frac{\mathrm{TST}^{*} \mathrm{I}}{100}
$$

em que: TTC $(\%)=$ Teor de taninos condensados em porcentagem; TST = Teor de sólidos totais (Equação 1); I = Índice de Stiasny (Equação 2).

O teor de não taninos será obtido pela diferença entre o teor de sólidos totais e o teor de taninos condensados obtido de cada amostra.

A extração dos taninos que foram utilizados no tratamento de efluentes foi em água, à temperatura de $70 \pm 5^{\circ} \mathrm{C}$, durante duas horas. Nas extrações, para cada 2,00 kg de ramos foram adicionados 10 litros de água (relação 5:1). Cada amostra foi submetida à fervura, em um digestor rotativo, com capacidade de 20 litros.

Cada amostra foi submetida a duas extrações. Assim, a relação final será de 1:10. Após cada extração, o material foi passado em uma peneira com tecido de "silk screen" e em um tecido de flanela, para a retenção de partículas finas. $\mathrm{O}$ extrato obtido foi homogeneizado e derramado em bandejas de alumínio de $5 \times 40 \times 60 \mathrm{~cm}$, e posto em uma estufa de ventilação forçada mantida a $70 \pm 3^{\circ} \mathrm{C}$, até a completa evaporação da umidade. $\mathrm{O}$ material seco obtido foi moído em 
um multiprocessador de uso doméstico e peneirado em peneira de 60 mesh.

A caracterização do efluente e etapas dos tratamentos inicialmente foi analisado o índice de turbidez/NTU, pH inicial e cor aparente. Estes parâmetros de controle foram adotados como os padrões de comparação para a análise do tratamento e determinação da eficiência na remoção das partículas indesejadas.

Após a separação da parte aquosa, foi iniciado o tratamento do efluentes por coagulação. Os ensaios foram realizados no Laboratório de Química da UFRN. As dosagens de coagulantes/floculantes foram otimizadas em função da turbidez e volume de lodo formado, e assim pôde-se determinar os melhores pHs de alcalinização e de coagulação do efluente.

As medidas de $\mathrm{pH}$ das amostras de efluentes coletadas e tratadas foram realizadas utilizando um pHmetro (marca Hanna instruments $\left.{ }^{\circledR}\right)$, sendo calibrado diariamente com soluções tampão de pH 4,0, 7,0 e 10,0. O índice de turbidez das amostras de efluentes bruto e tratado foi determinado utilizando um turbidímetro AP 2000 PoliControl ${ }^{\circledR}$. O processo de tratamento foi iniciado transferindo para um béquer o efluente bruto. Então, foi medido o pH e a turbidez inicial da amostra. Posteriormente adiciona-se lentamente uma solução de $\mathrm{NaOH}(10 \% \mathrm{~m} / \mathrm{v})$ sob agitação de $80 \mathrm{rpm}$ até o $\mathrm{pH}$ de alcalinização desejado. Após esse processo de alcalinização, foi diminuída a agitação do jar-test para $40 \mathrm{rpm}$ mantida por 20 minutos e adicionado lentamente o tanino até o $\mathrm{pH}$ de coagulação desejado. Por fim, foi adicionado $1 \mathrm{~mL}$ de polieletrólito (poliacrilamida) e sob agitação de $30 \mathrm{rpm}$ agitando-se por um minuto. $\mathrm{O}$ efluente recém-tratado então foi transferido para Cones Imhoff e ficou em repouso por $60 \mathrm{~min}$ para decantação para então, coletas de amostras para análises.

Para a avaliação dos resultados foi utilizado um delineamento inteiramente casualisado, onde as análises estatísticas foram processadas por meio do Sistema de Análises Estatísticas e Genéticas (SAEG), desenvolvido pela Central de Processamentos de Dados da Universidade Federal de Viçosa, sendo analisados o teor de sólidos totais (TST), índice de Stiasny (I), teor de taninos condensados (TTC).

\section{RESULTADOS}

Os testes foram feitos em duas etapas, onde na primeira verificou-se a turbidez nos dois reagentes e na testemunha, para então poder avaliar melhor a variação da turbidez, tendo sempre a turbidez inicial como base para a análise.

A Figura 1 mostra os resultados da turbidez na primeira parte do experimento, contendo 3 béqueres com diferentes substâncias para análise de turbidez. É notória a variação de turbidez entre os testes, onde se sobressaiu a turbidez do reagente químico, com maior incidência quando comparado com o reagente natural tanino, que teve a menor incidência de turbidez, constatando assim um ponto positivo no coagulante químico sobre o efluente.

$\mathrm{O}$ uso dos reagentes nas das três proporções não diferiram no $\mathrm{pH}$, sendo considerado ácido, nesse caso um ponto positivo, pois não altera a estrutura química da água e ainda quando usado com coagulante químico ajudou a controlar o $\mathrm{pH}$. Tendo em vista que os testes com essas proporções não diferem no $\mathrm{pH}$, conforme foi visto na literatura, isso pode ser explicado por não terem passado por nenhuma modificação química, deixando-o com mais capacidade de atuar no $\mathrm{pH}$, controlando e mantendo seu padrão (Figura 2). A média para o teor de sólidos totais, índice de Stiasny e teor de taninos condensados podem ser observadas na Figura 3.

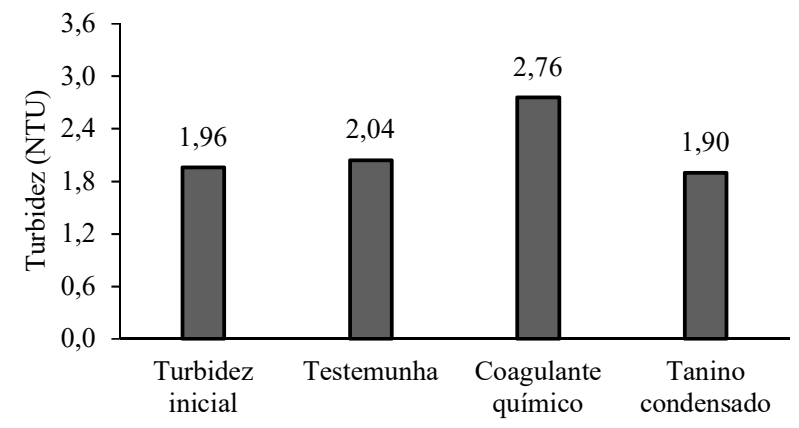

Figura 1. Teste de turbidez de cada reagente testado no efluente. Figure 1. Turbidity test of each reagent tested in the effluent.
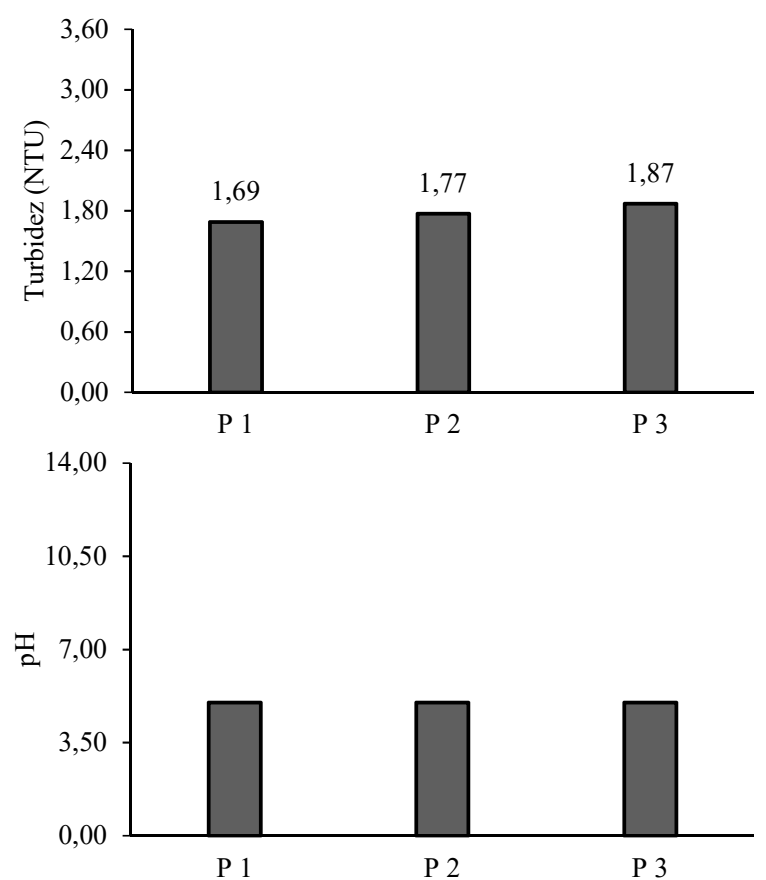

Figura 2. Testes de $\mathrm{PH}$ e turbidez no efluente em diferentes proporções.

Figure 2. PH-tests and turbidity in the effluent in different proportions.

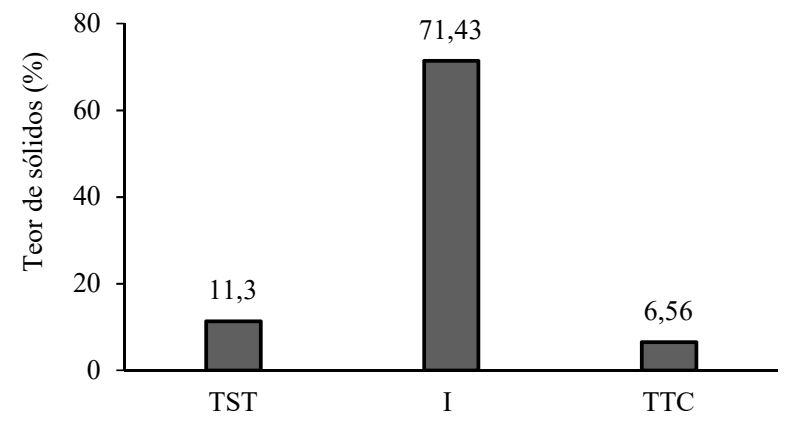

Figura 3. Médias (\%) do teor de sólidos totais (TST), índice de Stiasny (I) e teor de taninos condensados (TTC) da casca.

Figure 2. Means (\%) of total solids content (TST), Stiasny index (I) and condensed tannin content (TTC) of the bark. 


\section{DISCUSSÃO}

O uso dos taninos extraídos da casca da M. caealpiniifolia apresentou baixa eficiência na redução da turbidez no processo do tratamento de água, evidenciando que os usos dos coagulantes químicos são mais eficientes para este fim. Entretanto, este fator pode estar relacionado com falta de tratamento químico nos taninos, já que estudos utilizando o TANFLOC como o realizado por Coral et al. (2009), apontaram remoção de turbidez de aproximadamente $82 \%$. Os mesmos autores evidenciaram também que quanto maior a concentração do coagulante a base de tanino, menor será a redução da turbidez.

$\mathrm{O}$ uso de coagulantes naturais surge como alternativa eficaz para o tratamento de água e esgotos. Neste trabalho, o uso do tanino da casca da $M$. caealpiniifolia se mostrou eficiente como agente coagulante. Este resultado positivo pode estar relacionado com a estrutura química dos taninos, visto que os mesmos possuem características de adsorver e precipitar metais dissolvidos em água além de reduzir a toxicidade de águas com cianofíceas e bactérias clorofiladas (ÖZACAR; SENGIL, 2003).

$\mathrm{O}$ valor do $\mathrm{pH}$ se manteve constante mesmo com as diferentes proporções de taninos adicionados a água, classificado como ácido. Estes resultados se enquadram nos descritos na literatura. Couto Junior et al. (2012) evidenciaram a importância do uso dos taninos no tratamento de água para abastecimento que possuem $\mathrm{pH}$ entre 6,0 e 8,0 , pois, os mesmos atuarão de forma mais eficiente e sem a necessidade de uso de alcalinizastes.

O teor de taninos condensados presente na casca da $M$. caealpiniifolia se assemelha ao encontrado por Azevedo et al. (2018), onde ao avaliar a concentração destas substâncias na mesma espécie utilizada neste estudo em diferentes partes da planta, a casca foi a que apresentou maior concentração, em torno de 8,38\%. Entretanto, o valor encontrado nesta pesquisa foi superior ao obtido por Gonçalves; Lelis (2001), que foi de $2 \%$. Lins et al. (2019) ao quantificar o teor de taninos presentes na casca de espécies do bioma Caatinga, acharam valores entre 4,02 a 10,84\%, de modo que a espécie estudada se enquadra nos resultados obtidos pelos autores.

Uma das metodologias mais aplicadas para determinação do teor de taninos é o índice de Stiasny (I). Este método consiste em uma reação química em que ocorre a precipitação dos taninos do tipo flavanol através da condensação com formaldeído em meio ácido. Esses produtos apresentam alto peso molecular e são de difícil dissolução, de modo que, quanto maior for o índice de Stiasny, menor será a quantidade de outras substâncias como açúcares e gomas (GUANGCHENG et al., 1991; PIZZI; MITAL, 1994).

A casca da $M$. caealpiniifolia apresentou um I inferior ao encontrado por Azevedo et al. (2018) e superior ao obtido por Gonçalves; Lelis (2001) que foram, respectivamente, 91 e $20 \%$. Essas diferenças de valores podem esta relacionadas com o período de coleta, idade das árvores, localização dos indivíduos e o clima local (PAES et al., 2006).

$\mathrm{O}$ valor do I encontrado para a espécie estudada se assemelha com o de outras espécies nativas da região da Caatinga, como a Mimosa tenuiflora (Willd.) Poir. (71,12\%) e Mimosa arenosa (Willd.) Poir. (73,48\%) e superior a Anadenanthera colubrina (Vell.) Brenan var. cebil (Gris.) Alts. (52,88\%), sendo esta última a espécie mais utilizada na região Nordeste para extração de taninos destinados à indústria de curtimento de peles (PAES et al., 2006; AZEVEDO et al., 2015).

O teor de sólidos totais consiste no total de extrativos em forma de pó presentes na amostra (MEDEIROS et al., 2019). A $M$. caealpiniifolia apresentou um valor, para este parâmetro, superior ao obtido por Azevedo et al. (2018) que foi de 9,18\%.

\section{CONCLUSÕES}

Os taninos sem modificações químicas têm pouca eficiência na remoção de turbidez, mesmo quando associados a coagulantes químicos, no entanto, foi comprovado que o tanino possui aptidão a coagular. Já na análise do $\mathrm{pH}$ o tanino teve um ótimo desempenho, pois não alterou o valor desse parâmetro e ainda auxiliou quando usado junto com o coagulante químico. Com isso, a realização de pesquisas para melhorar o desempenho dos taninos na clarificação da água é de extrema importância para a ciência.

\section{AGRADECIMENTOS}

Ao Conselho Nacional de Desenvolvimento Científico e Tecnológico (CNPq), Universidade Federal do Rio Grande do Norte - UFRN, Escola Agrícola de Jundiaí - EAJ, Laboratório de Tecnologia de Produtos Florestais - LTPF, Grupo de Trabalho em Tecnologia da Madeira - GTMad e ao Laboratório de Tecnologia Ambiental - LabTam.

\section{REFERÊNCIAS}

AZEVÊDO, T. K. B.; PAES, J. B.; CALEGARI, L.; NASCIMENTO, W. B. do. Taninos de Jurema-Preta (Mimosa tenuiflora) para a produção de adesivo tanino formaldeído. Ciência Florestal, Santa Maria, v. 25, n. 2, p. 507-514, 2015.2 DOI: http://dx.doi.org/10.5902/1980509818470

AZEVÊDO, T. K. B.; CARDOSO, M. G. de A.; CAMPOS, D. B. P.; SOUZA, D. G.; NUNES, L. J.; GOMES, J. P. S.; CARNAVAL, A. A. de A.; SILVA, G. G. C. Substâncias tânicas presentes em partes da árvore sabiá (Mimosa caesalpiniifolia Benth.) em plantio comercial de 5 anos. Revista Agroecossistemas, Belém, v. 9, n. 2, p. 263-274, 2018. DOI: http://dx.doi.org/10.18542/ragros.v9i2.5033

BELTRÁN-HEREDIA， J.; SÁNCHES-MARTÍN， J.; GÓMEZ-MUÑOZ, M. C. New coagulant agents from tannin extracts: Preliminary optimisation studies. Journal Engineering Journal, v. 162, n. 3, p. 1019-1025, 2010. DOI: https://dx.doi.org/10.1016/j.cej.2010.07.011

CARNEIRO, A. C. O.; VITAL, B. R.; MENDES, A. F. N.; SANTOS, R. C.; CASTRO, R. V. O.; PINHEIRO, M. A. Parâmetros cinéticos de adesivos produzidos a partir de taninos de Anadenanthera peregrina e Eucalyptus grandis. Revista Árvore, Viçosa, v. 36, n. 4, p. 767-775, 2012. DOI: http://dx.doi.org/10.1590/S010067622012000400018

CORAL, L. A.; BERGAMASCO, R.; BASSETTI, F. J. Estudo da viabilidade de utilização do polímero natural (TANFLOC) em substituição ao Sulfato de Alumínio no tratamento de Águas para Consumo. International Workshop Advances in Cleaner Production, São Paulo, v. 2, 2009

COUTO JUNIOR, O. M.; STRÖHER, A. P.; BARROS, M. A. S. D.; PEREIRA, N. C. Caracterização e otimização do tratamento de efluente têxtil por coagulação-floculação, utilizando coagulante natural tanino. Revista Ciências 
Exatas e Naturais, Guarapuava, v. 14, n. 1, p. 79-90, 2012.

D'ALESSANDRO, O.; SELMI, G. J.; DEYÁ, C. ROMAGNOLI, R. Síntesis y caracterización de "tanatos" de lantano como inhibidores de la corrosión. Revista Matéria, Rio de Janeiro, v. 23, n. 2, 2018. DOI: http://dx.doi.org/10.1590/s1517-707620180002.0394

FERNANDES, M.; SKORONSKI, E.; TREVISAN, V.; ALVES, M. V.; ELY, C.; JOÃO, J. J. Aplicação de tanino como coagulante no reuso da água de lavação de automóveis e a utilização do lodo na agricultura. REDE Revista Eletrônica do PRODEMA Fortaleza, Fortaleza, v. 9, n. 1, p. 51-61, 2015.

GONÇALVES, C. A.; LELIS, R. C. C. Teores de taninos da casca e da madeira de cinco leguminosas arbóreas. Floresta e Ambiente, Seropédica, v. 8, n. 1, p. 167-173, 2001.

GUANGCHENG, Z.; YUNLU, L.; YAZAKI, Y. Extractive yields, Stiasny values and polyflavonoid contents in barks form six acacia species in Australia. Australian Forestry, Queensland, v. 554, n. 2, p. 154-156, 1991. DOI: https://dx.doi.org/10.1080/00049158.1991.10674572

HAMEED, Y. T.; IDRIS, A.; HUSSAIN, S. A.; ABDULLAH, N.; MAN, C. H.; SUJA, F. A tannin-based agent for coagulation and flocculation of municipal wastewater as a pretreatment for biofilm process. Journal of Cleaner Production, Amsterdam, v. 182, p.198-205, 2018. DOI: https://dx.doi.org/10.1016/j.jclepro.2018.02.044

HASLAM, E. Chemisty of vegetable tannins. London: Academic, 170 p. 1966.

IBGE INSTITUITO BRASILEIRO DE GEOGRAFIA E ESTATÍSTICA. Produção da extração vegetal e da silvicultura. 2017.31 v. 55 p. Disponível em: https://biblioteca.ibge.gov.br/visualizacao/periodicos/74/p evs_2016_v31.pdf. Acesso em 25 jun. 2019.

KEINERT JUNIOR, S.; WOLF, F. Alternativas de adesivos à base de taninos para madeira. Curitiba: FUPEF, (FUPEF Série Técnica). 25 p. 1984.

LINS, T. R. S.; BRAZ, R. L.; SILVA, T. C.; ARAUJO, E. C. G.; MEDEIROS, J. X.; REIS, C. Tannin Content of the Bark and Branch of Caatinga Species. Journal of Experimental Agriculture International, v. 31, n. 1, p. $1-8$, 2019. DOI: https://dx.doi.org/10.9734/jeai/2019/v31i130061

LOPES, E. C.; SANTOS, S. C. R.; PINTOR, A. M. A.; BOAVENTURA, R. A. R.; BOTELHO, C. M. S. Evaluation of a tannin-based coagulant on the decolorization of synthetic effluents. Journal of Environmental Chemical Engineering, v. 7, n. 3, 2019. DOI: https://dx.doi.org/10.1016/j.jece.2019.103125

MARTINS, A. A.; OLIVEIRA, R. M. S.; GUARDA, E. A. Potencial de uso de compostos orgânicos como, coagulantes, floculantes e adsorventes no tratamento de água e efluentes. Periódico Eletrônico Fórum Ambiental da Alta Paulista. v. 10, n. 12, p. 168-183, 2014. DOI: http://dx.doi.org/10.17271/1980082710122014913

MENEZES, K. M.; PEREIRA, J. V.; NÓBREGA, D. R. M.; FREITAS, A. F. R.; PEREIRA, M. S. V.; PEREIRA, A. V. Antimicrobial and Anti-Adherent in vitro Activity of Tannins Isolated from Anacardium occidentale Linn. (Cashew) on Dental Biolfilm Bacteria. Brazilian Research in Pediatric Dentistry and Integrated Clinic,
Campina Grande, v. 14, n. 3, p. 191-198, 2014. DOI: https://dx.doi.org/10.4034/PBOCI.2014.143.03

MEDEIROS, J. X.; CALEGARI, L.; SILVA, G. H.; OLIVEIRA, E.; PIMENTA, A. Measurement of tannic substances in forest species. Floresta e Ambiente, Seropédica, v. 25, n. 3, p. 1-8, 2018. DOI: http://dx.doi.org/10.1590/2179-8087.058916

ÖZACAR, M.; SENGIL, I. A. Evaluation of tannin biopolymer as a coagulante aid for coagulation of coloidal particles. Colloids and Surfaces A: Physicochemical and engineering aspects, Amsterdam, v. 229, n. 1-3, p. 85-96, 2003.

DOI: https://dx.doi.org/10.1016/j.colsurfa.2003.07.006

PAES, J. B.; DINIZ, C. E. F.; MARINHO, I. V.; LIMA, C. R. Avaliação do potencial tanífero de seis espécies florestais de ocorrência no semiárido brasileiro. Cerne, Lavras, v.12, n.3, p.232-238, jul./set., $2006 a$.

PAES, J. B.; MARINHO, I. V.; LIMA, R. A.; LIMA, C. R.; AZEVEDO, T. K. B. Viabilidade técnica dos taninos de quatro espécies florestais de ocorrência no semiárido brasileiro no curtimento de peles. Ciência Florestal. v.16, n.4, p.453-462, 2006b. DOI: http://dx.doi.org/10.5902/198050981927

PIZZI, A. Tanin-based adhesives. In: PIZZI, A. (Ed). Wood adhesives: chemistry and technology. New York: Marcell Dekker. 1993. p.177-246.

PIZZI, A.; MITTAL, K. L. Handbook of adhesive technology. New York: M. Dekker, 1994. 680 p.

SANTIAGO, S. B.; GONÇALVES, F. G.; LELIS, R. C. C.; SEGUNDINHO ALCÂNTARA, P. G. de.; PAES, J. B.; ARANTES, M. D. C. Colagem de madeira de eucalipto com adesivos naturais. Revista Matéria, v.23, n.3, 2018. DOI:

http://dx.doi.org/10.1590/s1517707620180003.0485

WENZL, H. F. J. The chemical technology of wood. New York: Academic, 692p. 1970 